\title{
Implementation of Concept Mapping As Learning Strategy to Improve Social Science Learning Outcomes in The Theme of Wonderful Diversity In My Country to The Fourth Grade Students of SDN 2 Prembun In Academic Year of 2019/2020
}

\author{
Sebelas Maret University \\ retnorahayu792@student.uns.ac.id
}

Retno Novianti Rahayu', Wahyudi ${ }^{2}$, Joharman ${ }^{3}$

\section{Article History}

accepted 01/06/2020

\begin{abstract}
The objectives of the research were: (1) to describe the steps in the implementation of concept mapping as learning strategy, (2) to improve social science learning outcomes in the theme of wonderful diversity in my country, and (3) to describe the obstacles and solutions in the implementation of concept mapping as learning strategy. The research was a collaborative classroom action research. The types of data were qualitative data and quantitative data. Data collection techniques included observation, interviews, and tests. The results of the research indicated that: (1) the steps in the implementation of concept mapping as learning strategy were: a) the teacher explained concept mapping as learning strategies to the students, b) the students worked in small groups, c) the students expressed the ideas, d) the students determined the main concepts, e) the teacher guided the students to create concept maps, $f$ ) the students presented the results of the discussion, $g$ ) the teacher provided feedback, $h$ ) the students summarized the lesson, i) the students made evaluation; (2) the implementation of the concept mapping as learning strategy improved students' learning outcomes, (3) the obstacle was found when the teacher gave feedback. The teacher did not give rewards. The solution was the teacher provided rewards for next meeting, for instance: reward stickers images.
\end{abstract}

Keywords: Concept Mapping, Learning Outcomes, Social Science

Abstrak: Tujuan penelitian ini yaitu: (1) mendeskripsikan langkah-langkah implementasi strategi belajar peta konsep, (2) meningkatkan hasil belajar IPS tema indahnya keragaman di negeriku, dan (3) mendeskripsikan kendala dan solusi implementasi strategi belajar peta konsep. Jenis penelitian ini adalah Penelitian Tindakan Kelas (PTK) Kolaboratif. Data yang digunakan berupa data kuantitatif dan kualitatif. Teknik pengumpulan data menggunakan observasi, wawancara dan tes. Hasil penelitian ini yaitu: (1) implementasi strategi belajar peta konsep untuk meningkatkan hasil belajar IPS dilaksanakan dengan langkah-langkah : a) memberitahu siswa bahwa akan diajarkan strategi belajar peta konsep, b) membuat kelompok kecil, c) mengemukakan ide atau gagasan, d) menentukan konsep utama, e) membimbing siswa membuat peta konsep, f) mempresentasikan hasil diskusi, g) memberikan umpan balik, h) merangkum pelajaran, dan i) evaluasi; (2) implementasi strategi belajar peta konsep dapat meningkatkan hasil belajar IPS tema indahnya keragaman di negeriku, (3) kendala dalam penelitian ini adalah pada langkah memberikan umpan balik guru belum memberikan bintang penghargaan. Solusinya guru menyiapkan stiker bintang untuk pertemuan berikutnya.

Kata Kunci: peta konsep, hasil belajar, IPS 


\section{PENDAHULUAN}

IImu Pengetahuan Sosial merupakan pelajaran di tingkat pendidikan sekolah dasar dan menengah. Menurut National Council for the Social Studies (Wahidmurni, 2017: 17) mendefinisikan social studies atau IImu Pengetahuan Sosial (IPS) sebagai ilmu yang terintegrasi dari ilmu-ilmu sosial dan humaniora serta terkoordinasi berbagai disiplin ilmu sosial. Di dalam Kurikulum 2013 (Permendikbud No. 104 Tahun 2014) dijelaskan hasil belajar belajar merupakan proses megumpulkan informasi mengenai pencapaian pembelajaran yang sudah dilaksanakan pada peserta didik dalam mengembangkan kompetensi sikap, pengetahuan, dan keterampilan yang dilakukan secara sistematis.

Berdasarkan observasi yang dilakukan pada pembelajaran IPS di kelas IV SDN 2 Prembun pada hari Kamis, 14 November 2019 didapatkan hasil sebagai berikut: (1) strategi yang digunakan strategi pembelajaran langsung yaitu berorientasi pada guru atau teacher center, dan (2) guru hanya meminta siswa membaca buku pegangan siswa tanpa memberi masukan menggunakan strategi belajar yang efektif untuk memahami materi.

Selain observasi, peneliti juga melakukan wawancara dengan guru kelas IV SDN 2 Prembun pada hari Sabtu, 16 November 2019 didapatkan hasil bahwa tingkat pemahaman siswa terhadap mupel IPS masih rendah, yaitu berdasarkan hasil Penilaian Tengah Semester (PTS) I hanya terdapat 42\% dari 12 siswa yang mendapat nilai di atas KKM yaitu sebanyak 5 siswa dan 7 siswa lainnya belum mendapatkan nilai diatas KKM, untuk KKM sekolah sebesar 70.

Berdasarkan masalah tersebut maka diperlukan solusi yaitu pembelajaran yang dapat membuat siswa belajar secara aktif, menyenangkan serta dapat menciptakan pembelajaran yang bermakna sehingga dapat meningkatkan hasil belajar siswa. Pembelajaran dengan menggunakan strategi belajar peta konsep akan memudahkan siswa dalam menyelesaikan tugas, menambah pengalaman dan mempertajam ingatan siswa dalam memahami materi. Dalam hal ini, peneliti akan menggunakan strategi belajar peta konsep.

Strategi belajar peta konsep menurut Novak dan Gowin (Yuniati, 2013) merupakan salah satu strategi yang dapat digunakan oleh guru untuk membimbing peserta didik menyusun konsep-konsep yang telah dipelajari agar terlihat keterkaitannya satu sama lain. Selain itu, menurut Martin (Rubiyah, 2018) menyatakan "a concept map is a top-down diagram showing the relationships between concepts, including cross connections among concepts, and their manifestations". Peta konsep didefinisikan sebagai top-down diagram yang menunjukkan hubungan antarkonsep termasuk hubungan silang antarkonsep, dan manifestasinya. Dalam penelitian ini, peneliti menggunakan peta konsep jenis pohon jaringan (network tree). Peta konsep jenis pohon jaringan dimulai dengan menempatkan ide-ide atau konsep-konsep dalam suatu susunan dari umum ke khusus kemudian ide-ide pokok dibuat dalam persegi empat, dan diberikan kata penghubung.

Berdasarkan uraian di atas, dapat dirumuskan masalah sebagai berikut: (1) bagaimana langkah-langkah implementasi strategi belajar peta konsep, (2) apakah implementasi strategi belajar peta konsep dapat meningkatkan hasil belajar IPS tema indahnya keragaman di negeriku pada siswa kelas IV SDN 2 Prembun tahun ajaram 2019/2020, dan (3) apakah kendala dan solusi implementasi strategi belajar peta konsep untuk meningkatkan hasil belajar IPS tema indahnya keragaman di negeriku pada siswa kelas IV SDN 2 Prembun tahun ajaran 2019/2020. Tujuan penelitian ini, yaitu : (1) mendeskripsikan langkah-langkah implementasi strategi belajar peta konsep, (2) meningkatkan hasil belajar IPS tema indahnya keragaman di negeriku, dan (3) mendeskripsikan kendala dan solusi implementasi strategi belajar peta konsep untuk meningkatkan hasil belajar IPS tema indahnya keragaman di negeriku pada siswa kelas IV SDN 2 Prembun tahun ajaran 2019/2020. 


\section{METODE PENELITIAN}

Metode penelitian yang digunakan adalah Penelitian Tindakan Kelas (PTK) secara kolaboratif antara peneliti dengan guru kelas IV SDN 2 Prembun. Kolaboratif yang dilakukan berupa kolaboratif dalam penyusunan RPP, pembuatan soal tes, dan praktik mengajar di kelas melalui implementasi strategi belajar peta konsep.

Data pada penelitian ini ada dua macam yaitu data kuantitatif berupa penilaian pengetahuan IPS tema indahnya keragaman di negeriku, dan data kualitatif berupa hasil wawancara terhadap guru dan siswa melalui implementasi strategi belajar peta konsep. Adapun sumber data yang digunakan yaitu siswa kelas IV, guru kelas IV, dan dokumen.

Teknik pengumpulan data yang digunakan ada dua yaitu teknik nontes dan tes. Teknik nontes terdiri dari observasi, wawancara, dan dokumentasi. Sedangkan teknik tes yaitu tes hasil belajar IPS. Adapun alat pengumpulan data yang digunakan yaitu lembar observasi, pedoman wawancara, dan kisi-kisi tes evaluasi IPS.

Teknik uji validitas data pada penelitian ini menggunakan teknik triangulasi yaitu triangulasi teknik dan sumber. Triangulasi teknik yang digunakan yaitu observasi, wawancara, dan tes. Adapun triangulasi sumber yang digunakan yaitu siswa, guru dan dokumen. Teknik analisis data yang digunakan dalam penelitian ini yaitu reduksi data, penyajian data, dan penarikan kesimpulan sesuai model analisis data menurut Miles dan Huberman (Sugiyono, 2016).

\section{HASIL DAN PEMBAHASAN}

Implementasi strategi belajar peta konsep untuk meningkatkan hasil belajar IPS tema indahnya keragaman di negeriku pada siswa kelas IV SDN 2 Prembun dilakukan dalam tiga siklus. Masing-masing siklus terdiri dari dua pertemuan dengan alokasi waktu 70 menit setiap pertemuan.

Proses pembelajaran dilaksanakan dengan langkah-langkah: (1) memberitahu siswa bahwa akan diajarkan strategi belajar peta konsep, (2) membuat kelompok kecil, (3) mengemukakan ide atau gagasan, (4) menentukan konsep utama, (5) membimbing siswa membuat peta konsep, (6) mempresentasikan hasil diskusi, (7) memberikan umpan balik, (8) merangkum pelajaran, (9) evaluasi. Langkah-langkah yang digunakan oleh peneliti mengacu pada langkah-langkah yang dikemukakan oleh (Khofifah, 2013) dan (Yusoh, 2017) yang kemudian disimpulkan menjadi langkah yang disebutkan di atas. Hasil observasi implementasi strategi belajar peta konsep mengalami peningkatan pada setiap siklusnya hingga mencapai indikator kinerja penelitian yang ditargetkan sebesar $85 \%$.

\begin{tabular}{lcccccccc}
\hline \multirow{2}{*}{$\begin{array}{l}\text { Langkah } \\
\text { Implementasi Strategi }\end{array}$} & \multicolumn{2}{c}{ Siklus I } & \multicolumn{2}{c}{ Siklus II } & \multicolumn{2}{c}{ Siklus III } & \multicolumn{2}{c}{ Rata-rata } \\
\cline { 2 - 9 } $\begin{array}{l}\text { Belajar Peta Konsep } \\
(\%)\end{array}$ & $\begin{array}{c}\mathrm{S} \\
(\%)\end{array}$ & $\begin{array}{c}\mathrm{G} \\
(\%)\end{array}$ & $\begin{array}{c}\mathrm{S} \\
(\%)\end{array}$ & $\begin{array}{c}\mathrm{G} \\
(\%)\end{array}$ & $\begin{array}{c}\mathrm{S} \\
(\%)\end{array}$ & $\begin{array}{c}\mathrm{G} \\
(\%)\end{array}$ & $\begin{array}{c}\mathrm{S} \\
(\%)\end{array}$ \\
\hline $\begin{array}{l}\text { Memberitahusiswa } \\
\text { bahwwa akandiajarkan } \\
\text { strategi belajar peta } \\
\text { konsep }\end{array}$ & 87,50 & 87,50 & 92,71 & 92,71 & 96,87 & 94,75 & 92,36 & 91,65 \\
\hline $\begin{array}{l}\text { Membuat kelompok } \\
\text { kecil }\end{array}$ & 91,67 & 89,58 & 90,63 & 89,58 & 93,75 & 94,75 & 92,01 & 91,03 \\
\hline $\begin{array}{l}\text { Mengemukakanide } \\
\text { ataugagasan }\end{array}$ & 87,50 & 87,50 & 90,63 & 89,58 & 91,67 & 89,58 & 89,93 & 88,89 \\
\hline $\begin{array}{l}\text { Menentukankonsep } \\
\text { utama }\end{array}$ & 87,50 & 87,50 & 87,50 & 89,58 & 91,67 & 91,67 & 88,89 & 89,58 \\
\hline $\begin{array}{l}\text { Membimbing siswa } \\
\text { membuatpeta konsep }\end{array}$ & 87,50 & 86,46 & 92,59 & 92,71 & 94,79 & 92,71 & 91,61 & 90,62 \\
\hline $\begin{array}{l}\text { Mempresentasikan } \\
\text { hasil diskusi }\end{array}$ & 95,83 & 87,50 & 93,75 & 89,58 & 93,75 & 91,67 & 94,44 & 89,58 \\
\hline $\begin{array}{l}\text { Memberikan umpan } \\
\text { balik }\end{array}$ & 81,25 & 81,25 & 90,63 & 88,54 & 90,63 & 92,71 & 87,50 & 87,50 \\
\hline Merangkumpelajaran & 68,75 & 52,09 & 93,75 & 87,50 & 93,75 & 89,58 & 85,42 & 76,39 \\
\hline Evaluasi & 87,50 & 91,67 & 87,50 & 87,50 & 91,67 & 91,67 & 88,89 & 90,28 \\
\hline Rata-rata & 86,11 & 83,45 & 91,07 & 89,69 & 93,17 & 92,12 & 90,11 & 88,39 \\
\hline
\end{tabular}

Gambar 1. Hasil Observasi Implementasi Strategi Belajar Peta Konsep 
Berdasarkan tabel 1, diketahui bahwa proses pembelajaran di siklus I, siklus II, dan siklus III selalu mengalami peningkatan. Hasil capaian guru dalam mengajar pada siklus I yaitu $86,11 \%$, pada siklus II 91,07\%, dan pada siklus III 93,17\%. Hasil capaian siswa dalam pembelajaran pada siklus I yaitu $83,45 \%$, pada siklus II yaitu $89,69 \%$, dan pada siklus III mencapai $92,12 \%$.

\begin{tabular}{lcccccc}
\hline \multirow{2}{*}{ Keterangan } & \multicolumn{2}{c}{ Siklus I } & \multicolumn{2}{c}{ Siklus II } & \multicolumn{2}{c}{ Siklus III } \\
\cline { 2 - 7 } & Pert. 1 & Pert.2 & Pert.1 & Pert.2 & Pert.1 & Pert.2 \\
\hline Nilai Tertinggi & 97,00 & 100 & 100 & 97,00 & 100 & 100 \\
\hline Nilai Terendah & 43,00 & 63,00 & 73,00 & 80,00 & 80,00 & 83,00 \\
\hline Rata-rata & 78,67 & 86,75 & 88,33 & 89,50 & 90,83 & 93,00 \\
\hline Tuntas & 10 & 11 & 11 & 12 & 12 & 12 \\
\hline Belum Tuntas & 2 & 1 & 1 & 0 & 0 & 0 \\
\hline
\end{tabular}

Gambar 2. Analisis Hasil Belajar Siswa Siklus I, II, dan III

Berdasarkan tabel di atas, dapat diketahui bahwa ketuntasan hasil belajar siswa selalu mengalami peninggkatan di setiap siklus. Pada siklus I persentase ratarata siswa yang tuntas yaitu $87,50 \%$, pada siklus II $95,83 \%$, dan pada siklus III $100 \%$. Hasil akhir pada siklus III sudah mencapai target yang ditentukan.

Dengan demikian implementasi strategi belajar peta konsep dapat meningkatkan hasil belajar IPS tema indahnya keragaman di negeriku yang dilihat dari persentase siswa yang memenuhi ketercapaian target dari siklus I-III. Hasil penelitian ini memperkuat penelitian yang dilakukan oleh (Khofifah, 2013) yang menunjukan bahwa strategi belajar peta konsep dapat meningkatkan kualitas pembelajaran IPS. Hal ini juga dilakukan oleh (Aisah, 2015) yang menunjukkan bahwa penggunaan peta konsep dapat meningkatkan hasil belajar siswa kelas IV. Selain itu, (Muchtar, 2016) menyatakan bahwa penerapan strategi peta konsep dapat digunakan untuk meningkatkan hasil belajar siswa kelas IV.

Kendala implementasi strategi belajar peta konsep untuk meningkatkan hasil belajar IPS tema indahnya keragaman di negeriku pada siswa kelas IV SDN 2 Prembun tahun ajaran 2019/2020 yaitu: (1) guru belum memberikan bintang penghargaan, (2) siswa kurang aktif dalam memberikan tanggapan hasil diskusi, (3) guru belum maksimal dalam memberikan arahan mengerjakan soal evaluasi, (4) siswa belum aktif dalam merangkum pelajaran, (5) guru kurang melibatkan siswa dalam menyimpulkan materi, (6) terdapat siswa yang tergesah-gesah dalam mengerjakan LKS, dan (7) belum semua siswa merangkum pelajaran. Adapun solusi untuk mengatasi kendala tersebut yaitu: ((1) guru menyiapkan stiker bintang untuk pertemuan berikutnya, (2) mengarahkan guru untuk meminta siswa memberikan tanggapan saat presentasi, (3) guru memberikan arahan mengerjakan soal evaluasi secara rinci, (4) guru memotivasi siswa agar antusias dalam merangkum pelajaran, (5) guru mengajak siswa untuk menarik kesimpulan bersama-sama, (6) guru menegur siswa agar mengerjakan dengan teliti, dan (7) guru membimbing siswa saat merangkum pelajaran yaitu tentang hal-hal apa saja yang perlu ditulis.

\section{SIMPULAN DAN SARAN}

Berdasarkan rumusan masalah, hasil penelitian, dan pembahasan, berikut adalah simpulan dalam penelitian ini:

1. Implementasi strategi belajar peta konsep untuk meningkatkan hasil belajar IPS tema indahnya keragaman di negeriku pada siswa kelas IV SDN 2 Prembun tahun ajaran 2019/2020 dilaksanakan dengan langkah-langkah: (1) memberitahu siswa bahwa akan diajarkan strategi belajar peta konsep, (2) membuat kelompok kecil, (3) mengemukakan ide atau gagasan, (4) menentukan konsep utama, (5) membimbing 
siswa membuat peta konsep, (6) mempresentasikan hasil diskusi, (7) memberikan umpan balik, (8) merangkum pelajaran, (9) evaluasi.

2. Implementasi strategi belajar peta konsep untuk meningkatkan hasil belajar IPS tema indahnya keragaman di negeriku pada siswa kelas V SDN 2 Prembun tahun ajaran 2019/2020, ditunjukkan dengan peningkatan persentase siswa pada setiap siklus yang memenuhi ketercapaian target indikator penelitian sebesar $85 \%$.

3. Kendala penerapan implementasi strategi belajar peta konsep untuk meningkatkan hasil belajar IPS tema indahnya keragaman di negeriku pada siswa kelas V SDN 2 Prembun tahun ajaran 2019/2020 yaitu: (1) guru belum memberikan bintang penghargaan, (2) siswa kurang aktif dalam memberikan tanggapan hasil diskusi, (3) guru belum maksimal dalam memberikan arahan mengerjakan soal evaluasi, (4) siswa belum aktif dalam merangkum pelajaran, (5) guru kurang melibatkan siswa dalam menyimpulkan materi, (6) terdapat siswa yang tergesah-gesah dalam mengerjakan LKS, dan (7) belum semua siswa merangkum pelajaran. Adapun solusi untuk mengatasi kendala tersebut yaitu: ((1) guru menyiapkan stiker bintang untuk pertemuan berikutnya, (2) mengarahkan guru untuk meminta siswa memberikan tanggapan saat presentasi, (3) guru memberikan arahan mengerjakan soal evaluasi secara rinci, (4) guru memotivasi siswa agar antusias dalam merangkum pelajaran, (5) guru mengajak siswa untuk menarik kesimpulan bersama-sama, (6) guru menegur siswa agar mengerjakan dengan teliti, dan (7) guru membimbing siswa saat merangkum pelajaran yaitu tentang hal-hal apa saja yang perlu ditulis.

Berdasarkan simpulan hasil tindakan penelitian, maka dapat disampaikan saransaran sebagai berikut: (1) siswa hendaknya lebih fokus dan berperan aktif dalam langkah strategi belajar peta konsep, berani menyampaikan pendapat, dan berani bertanya jika ada materi yang belum dipahami, (2) guru sebaiknya lebih berusaha dalam mengarahkan siswa untuk fokus dan aktif dalam langkah strategi belajar peta konsep agar siswa dapat memahami materi yang disampaikan, (3) sebaiknya sekolah menyediakan fasilitas, sarana, dan prasarana serta mendukung guru untuk berinovasi dalam menggunakan strategi atau teknik untuk meningkatkan kualitas pembelajaran, dan (4) peneliti lain hendaknya membuat kegiatan pembelajaran yang lebih inovatif dan kreatif sesuai dengan perkembangan ilmu pengetahuan yang semakin maju. Salah satunya, yaitu dengan mengimplementasikan strategi belajar peta konsep.

\section{DAFTAR PUSTAKA}

Aisah. (2015). Peningkatan Pembelajaran Sumber Daya Alam Menggunakan Peta Konsep di Sekolah Dasar. Jurnal Saung Guru, 7(2), 134-149.

Khofifah, N. (2013). Peningkatan Kualitas Pembelajaran IPA Melalui Strategi Belajar Peta Konsep Pada Siswa Kelas VB SDN Purwoyoso 03 Semarang. Skripsi Tidak Dipublikasikan. Universitas Negeri Semarang.

Muchtar, Imam, dkk. (2016). Penerapan Strategi Peta Konsep Jenis Pohon Jaringan untuk Meningkatkan Aktivitas dan Hasil Belajar Siswa Kelas IV Tema CitaCitaku di SDN Kebonsari 05 Jember. Jurnal Pendidikan Sekolah Dasar, 4(3), 176-183.

Presiden Republik Indonesia. (2013). Peraturan Menteri Pendidikan dan Kebudayaan Republik Indonesia No. 104 Tahun 2014 tentang Pembelajaran pada Pendidikan Dasar dan Pendidikan Menengah. Jakarta: Presiden Republik Indonesia.

Rubiyah, dkk. (2018). Implementing Concept Mapping Technique To Improve Students Descriptive Writing Ability. Journal of Language and Teaching, 21(1), 65-74.

Sugiyono. (2016). Metode Penelitian Pendidikan (Pendekatan Kuantitatif, Kualitatif, dan $R \& D$ ). Bandung: Alfabeta

Wahidmurni. (2017). Metodologi Pembelajaran IPS. Yogyakarta: Ar-Ruzz Media 
Volume 8 Nomor 2 Tahun 2020

Yuniati, S. (2013). Peta Konsep (Mind Mapping) dalam Pembelajaran Struktur Aljabar. Gamatika, 3(2), 134-135.

Yusoh, Mareeyah. (2017). Penerapan Model Pembelajaran Concept Mapping Dalam Meningkatkan Hasil Belajar Al-Quar'an Hadis Di Kelas VII Tingkat Tsanawiyah Ma'ad As-Saqafah Al-Islamiah Patani Selatan Thailand. Skripsi Tidak Dipublikasikan. Institut Agama Islam Negeri Raden Intan Lampung. 